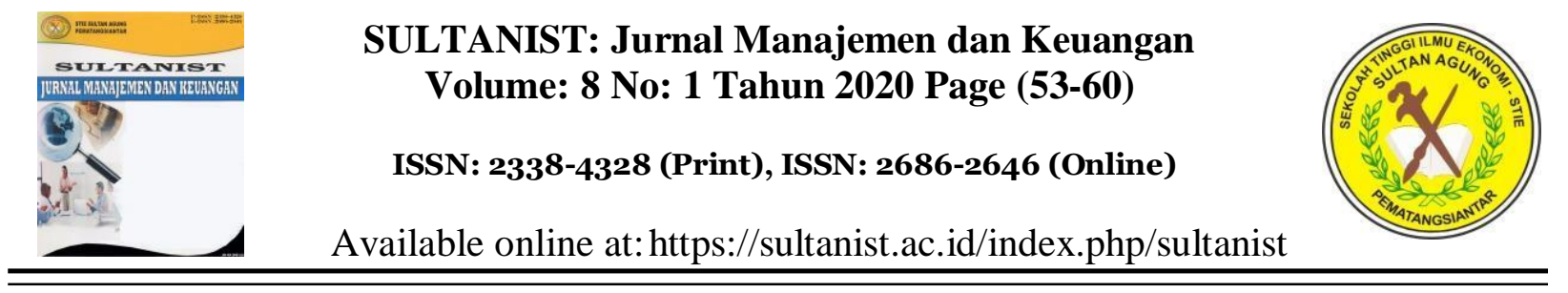

\title{
PENGARUH SIKAP KONSUMEN DAN PERSEPSI KONSUMEN TERHADAP KEPUTUSAN PEMBELIAN PADA MINI MARKET MAWAR BALIMBINGAN
}

\author{
Siti Fadhila ${ }^{1}$, Darwin Lie $^{2}$, Andy Wijaya ${ }^{3}$, Fitria Halim ${ }^{4}$ \\ Program Studi Manajemen, Sekolah Tinggi Ilmu Ekonomi Sultan Agung \\ dhillalala710@gmail.com \\ Program Studi Manajemen, Sekolah Tinggi Ilmu Ekonomi Sultan Agung, \\ darwin@stiesultanagung.ac.id, andywijaya@ stiesultanagung.ac.id, \\ fitriahalim2839@stiesultanagung.ac.id
}

\begin{abstract}
Abstrak
Mini Market Mawar Balimbingan berdiri pada tahun 2002 dengan alamat Jl. Besar Tanah Jawa, Balimbingan Kecamatan Tanah Jawa. Mini Market Mawar berdiri dengan tujuan memberikan kenyamanan kepada masyarakat dalam berbelanja kebutuhan sehari-hari dengan mengambil konsep pasar yang lebih modern. Dimana kebanyakan pada saat itu masyarakat hanya mengandalkan pasar tradisional dan warung-warung terdekat untuk memenuhi kebutuhan sehari-harinya. Penulis menggunakan dua metode penelitian yaitu penelitian lapangan dan penelitian kepustakaan metode pengumpulan data dengan observasi, wawancara dan dokumentasi yang bersumber dari data primer dan data sekunder dan dianalisis dengan uji asumsi klasik, analisis deskriptif kualitatif, dan analisis deskriptif kuantitatif. Kesimpulan dari penelitian ini adalah sikap konsumen dan persepsi konsumen berpengaruh terhadap keputusan pembelian. Hasil tersebut dinyatakan dalam hasil model persamaan $\hat{\mathrm{Y}}=20,454+0,674 \mathrm{X}_{1}+$ $0,398 \mathrm{X}_{2}$ yang artinya terdapat pengaruh positif antara sikap konsumen dan persepsi konsumen terhadap keputusan pembelian pada Mini Market Mawar Balimbingan.
\end{abstract}

Kata kunci: Sikap Konsumen, Persepsi Konsumen, dan Keputusan Pembelian

\section{THE EFFECT OF CONSUMER ATTITUDES AND CONSUMER PERCEPTIONS ON THE PURCHASING DECISIONS AT MINI MARKET MAWAR BALIMBINGAN}

\begin{abstract}
Mini Market Mawar Balimbingan founded in 2002 with Great street address Tanah jawa, subdistrict of Balimbingan. Mini Market Mawar stood with the intention of providing convenience to the public in shopping for daily needs by taking a more modern market concepts. At the time where most communities on traditional markets and stalls nearby to meet the daily needs. The author uses two methods of research thats research library and field research data gathering method with observation, interview and documentation are sourced from primary data and secondary data and analyzed with a classic assumption test, a descriptive analysis of qualitative, quantitative and descriptive analysis.The conclusions of this research are consumer attitudes and perceptions affect consumer purchasing decisions. The results are expressed in the results of the model equations $=\hat{Y} 20.454+0,674 X 1+0$, $398 X 2$ meaning that there is a positive influence consumer attitudes and perceptions among consumers against purchasing decisions on the Mini Market Mawar Balimbingan.
\end{abstract}

Keywords: Consumer Attitudes, Consumer Perceptions, and Purchasing Decisions 


\section{PENDAHULUAN}

Salah satu bisnis usaha yang mampu bertahan di era globalisasi ini yaitu Mini Market Mawar Balimbingan yang menjadi salah satu pilihan masyarakat dalam melakukan pembelian. Hal ini dikarenakan Mini Market Mawar menyediakan berbagai jenis produk yang di butuhkan masyarakat dengan harga terjangkau, letak yang strategis juga menjadikan Mini Market Mawar menjadi salah satu toko yang menjadi pilihan masyarakat dalam melakukan keputusan pembelian.

Fenomena pada keputusan pembelian pada dimensi evaluasi alternatif belum optimal karena Mini Market Mawar Balimbingan memiliki banyak pesaing di bidang usaha yang sama menyebabkan banyaknya alternatif pilihan yang dilakukan konsumen sehingga keputusan pembelian di tempat tersebut cenderung menurun. Sementara pada dimensi evaluasi pascapembelian, kurangnya ketersediaan produk dengan jenis merek yang berbeda membuat konsumen memilih melakukan pembelian di tempat lain.

Salah satu faktor yang mempengaruhi keputusan pembelian yaitu sikap konsumen. Hal ini sesuai dengan teori Kotler dan Gary (2008), bahwa keputusan pembelian konsumen memiliki dua faktor yang bisa berada antara niat pembelian dan keputusan pembelian. Faktor pertama adalah sikap orang lain, dan faktor yang kedua adalah faktor situsional yang tidak diharapkan. Ada beberapa dimensi sikap konsumen yang akan mempengaruhi keputusan pembelian, antara lain komponen kognitif, komponen afektif , komponen perilaku.

Fenomena sikap konsumen pada komponen kognitif, kurang optimal karena lambatnya pelayanan yang diberikan oleh pegawai Mini Market Mawar Balimbingan kepada konsumen yang membutuhkan bantuan saat melakukan pembelian yang menyebabkan konsumen memilih melakukan pembelian di tempat lain. Sedangkan pada dimensi komponen perilaku masih kurang optimal karena kurangnya kesadaran konsumen saat melakukan pembelian yaitu tidak merapikan kembali barang-barang yang tidak jadi dibeli menyebabkan konsumen lain sulit untuk menemukan barang yang di cari.

Selain sikap konsumen faktor lain yang mempengaruhi keputusan pembelian adalah persepsi konsumen. Seperti yang dijelaskan oleh Sumarwan (2002), bahwa pengaruh persepsi konsumen terhadap keputusan pembelian terjadi ketika seorang konsumen mampu melihat realitas di luar dirinya atau dunia sekelilingnya. Konsumen seringkali memutuskan pembelian suatu produk berdasarkan persepsinya terhadap produk tersebut. Dalam penelitian ini, persepsi konsumen menggunakan tiga dimensi yaitu: atensi selektif, distorsi selektif, dan retensi selektif.

Fenomena persepsi konsumen pada dimensi atensi selektif, kurangnya perhatian Mini Market Mawar Balimbingan dalam memberikan informasi terkait harga-harga barang tertentu sehingga membuat konsumen bingung dalam memutuskan pembelian barang yang diinginkan. Sementara itu fenomena pada dimensi retensi selektif terjadi karena konsumen lebih memilih melakukan pembelian di tempat lain apabila tidak menemukan produk yang di cari di Mini Market Mawar Balimbingan. Adapun tujuan penelitian ini adalah untuk mengetahui gambaran sikap konsumen, persepsi konsumen, dan keputusan pembelian pada Mini Market Mawar Balimbingan dan untuk mengetahui pengaruh sikap konsumen dan persepsi konsumen terhadap keputusan pembelian pada Mini Market Mawar Balimbingan baik secara simultan maupun parsial.

\section{LANDASAN TEORI}

\section{Sikap Konsumen}

Menurut Setiadi (2003), "sikap artinya perasaan senang atau tidak senang konsumen terhadap objek yang dipertanyakan". Menurut Schiffman dan Leslie (2007), "sikap adalah kecenderungan yang dipelajari dalam berperilaku dengan cara yang menyenangkan terhadap suatu objek tertentu". Menurut Winardi (2009), "sikap adalah determinan perilaku karena mereka berkaitan dengan persepsi, kepribadian, dan motivasi”. 


\section{SULTANIST: Jurnal Manajemen dan Keuangan, Vol X (x), 2020}

Menurut Schiffman dan Leslie (2007), sikap terdiri dari tiga komponen utama:

1. Komponen Kognitif

Komponen pertama dari model sikap tiga komponen terdiri dari berbagai kognisi seseorang yaitu pengetahuan dan persepsi yang diperoleh berdasarkan kombinasi pengalaman langsung dengan obyek sikap dan informasi yang berkaitan dari berbagai sumber.

2. Komponen Afektif

Emosi atau perasaan konsumen mengenai produk atau merek tertentu merupakan komponen afektif dari sikap tertentu.

3. Komponen Perilaku

Model sikap dari tiga komponen terakhir yang berhubungan dengan kemungkinan atau kecenderungan bahwa individu akan melakukan tindakan khusus atau berperilaku dengan cara tertentu terhadap objek sikap tertentu.

\section{Persepsi Konsumen}

Menurut Kotler dan Kevin (2009), "persepsi konsumen adalah proses dimana kita memilih, mengatur, dan menerjemahkan masukan informasi untuk menciptakan gambaran dunia yang berarti. Menurut Schiffman dan Leslie (2007), "persepsi didefinisikan sebagai proses yang dilakukan individu untuk memilih, mengatur, dan menafsirkan stimuli ke dalam gambar yang berarti dan masuk akal mengenai dunia.

Menurut Kotler dan Kevin (2009), proses persepsi konsumen yaitu:

1. Atensi Selektif

Atensi/perhatian adalah alokasi pemrosesan kapasitas terhadap beberapa rangsangan. Atensi selektif berarti bahwa pemasar harus bekerja keras untuk menarik atensi konsumen. Tantangan sebenarnya adalah menjelaskan rangsangan mana yang akan diperhatikan orang.

2. Distorsi Selektif

Distorsi selektif (selective distortion) adalah kecenderungan untuk menerjemahkan informasi dengan cara yang sesuai dengan konsepsi awal kita. Konsumen sering mendistorsi informasi agar konsisten dengan keyakinan dan ekspektasi dari merek dan produk yang sudah ada sebelumnya.

3. Retensi Selektif

Retensi selektif (selective retention) cenderung mengingat poin bagus tentang sebuah produk yang kita sukai dan melupakan poin bagus tentang produk pesaing.

\section{Keputusan Pembelian}

Menurut Kotler dan Gary (2008), "keputusan pembelian (purcase decision) adalah membeli merek yang paling disukai, tetapi dua faktor bisa berada antara niat pembelian dan keputusan pembelian". Menurut Setiadi (2003), "pengambilan keputusan konsumen (customer decision making) adalah proses integrasi yang mengombinasikan pengetahuan untuk mengevaluasi dua atau lebih perilaku alternatif dan memilih salah satu diantaranya". Menurut Boyd,et.al (2000), "pengambilan keputusan konsumen merupakan proses pemecahan masalah melalui proses mental yang hampir sama dalam memutuskan produk dan merek apa yang akan dibeli".

Menurut Kotler dan Gary (2008), proses keputusan pembeli terdiri dari lima tahap yaitu:

1. Pengenalan Kebutuhan (need recognition) Pembeli menyadari suatu masalah atau kebutuhan. Kebutuhan dapat dipicu oleh rangsangan internal ketika salah satu kebutuhan normal seseorang seperti rasa lapar, haus, timbul pada tingkat yang cukup tinggi sehingga menjadi dorongan.

2. Pencarian Informasi (information search)

Pencarian informasi merupakan tahap proses keputusan pembelian dimana konsumen ingin mencari informasi lebih banyak, konsumen mungkin hanya memperbesar atau melakukan pencarian informasi secara akif.

3. Evaluasi Alternatif (alternative evaluation)

Evaluasi alternatif yaitu bagaimana konsumen memproses informasi untuk sampai pada pemiilihan merek. Tahap proses keputusan pembeli pada evaluasi alternatif, dimana konsumen mengunakan informasi untuk mengevaluasi merek alternatif dalam sekelompok pilihan. 
4. Keputusan Pembelian (purchase decision)

Keputusan pembelian adalah membeli merek yang paling disukai, tetapi dua faktor bisa berada antara niat pembelian dan keputusan pembelian.

5. Perilaku Pasca Pembelian (postpurchase behavior)

Tahap proses pembeli dimana konsumen mengambil tindakan selanjutnya setelah pembelian, berdasarkan kepuasan atau ketidakpuasan mereka.

seseorang sejauh mana produk bisa memenuhi harapan dan evaluasi konsumen tentang sejauh mana produk benar-benar memenuhi harapan.

\section{METODE PENELITIAN}

Dalam penelitian ini, penulis menggunakan desain penelitian kepustakaan dan lapangan. Objek penelitian adalah konsumen Mini Market Balimbingan, tempat penelitian dilakukan pada Mini Market Balimbingan. Jenis data yang digunakan adalah data kualitatif dan kuantitatif dan sumber data berasal dari data primer dan data sekunder. Data penelitian dikumpulkan dengan melakukan wawancara, dokumentasi dan penyebaran kuesioner. Analisis data meliputi analisis data kualitatif dan analisis kuantitatit.

\section{PEMBAHASAN}

\section{Analisis Deskriptif Kualitatif}

Analisis deskriptif dimaksudkan untuk mendapatkan gambaran sikap konsumen, persepsi konsumen terhadap keputusan pembelian konsumen pada Mini Market Balimbingan. Adapun penetapan kriteria nilai rata-rata jawaban responden tersebut dimasukkan ke dalam kelas-kelas interval berikut:

\section{Tabel 1. Nilai Interval dan Kategori} Jawaban Responden

\begin{tabular}{|c|c|}
\hline Nilai Interval & Kategori \\
\hline $1,00-1,80$ & Sangat Tidak Baik (STB) \\
\hline $1,81-2,60$ & Tidak Baik (TB) \\
\hline $2,61-3,40$ & Cukup Baik (CB) \\
\hline $3,41-4,20$ & Baik (B) \\
\hline $4,21-5,00$ & Sangat Baik (SB) \\
\hline
\end{tabular}

Sumber: hasil pengolahan data (2019)

\section{Gambaran Sikap Konsumen Pada Mini Market Balimbingan}

Secara keseluruhan variabel sikap konsumen memiliki nilai rata-rata 3,71 dengan ketegori jawaban baik. Untuk nilai tertinggi dengan rata-rata 3,89 dengan ketegori jawaban baik yaitu pada dimensi komponen perilaku dengan patuh dan taat. Nilai terendah dengan nilai rata-rata 3,35 dengan kriteria jawaban baik pada dimensi komponen kognitif dengan indikator kesan yang muncul terkait objek.

\section{Gambaran Persepsi Konsumen Pada Mini Market Balimbingan}

Secara keseluruhan persepsi konsumen memiliki nilai rata-rata 3,61 dengan kriteria baik. Untuk nilai tertinggi dapat dilihat pada dimensi retensi selektif pada indikator keyakinan terhadap produk dengan nilai ratarata 3,73 dengan kriteria jawaban baik. Sedangkan untuk nilai terendah terdapat pada dimensi retensi selektif pada indikator mengabaikan pesaing dengan nilai rata-rata 3,38 dengan kriteria jawaban cukup baik.

\section{Gambaran Keputusan Pembelian Pada Mini Market Balimbingan}

Secara keseluruhan variabel keputusan pembelian memiliki nilai rata-rata 3,73 dengan kriteria jawaban baik. Untuk nilai tertinggi yaitu 3,95 dengan kriteria jawaban baik pada dimensi pengenalan masalah dengan indikator ketersediaan kebutuhan. Nilai terendah dengan nilai rata-rata 3,38 dengan kriteria jawaban cukup baik pada dimensi evaluasi alternatif dengan indikator sikap terhadap alternatif pilihan produk.

\section{Analisis Deskriptif Kuantitatif}

\section{Analisis Regresi Linier Berganda}

Penelitian ini memiliki tujuan untuk menganalisis pengaruh sikap konsumen dan persepsi konsumen terhadap keputusan pembelian. Dalam penelitian ini untuk analisis data menggunakan analisis regresi linier berganda. Analisis regresi linier berganda digunakan untuk mengetahui pengaruh variabel bebas $(\mathrm{X})$ dan variabel terikat $(\mathrm{Y})$, dimana $X$ adalah sikap konsumen dan persepsi konsumen, lalu Y adalah keputusan pembelian. 
Maka dilakukan perhitungan menggunakan program aplikasi SPSS versi 21 dengan hasil hitung regresi sebagai berikut:

Tabel 2. Hasil Regresi Linear Berganda

\begin{tabular}{|c|c|c|c|c|}
\hline \multirow{2}{*}{\multicolumn{2}{|c|}{ Model }} & \multicolumn{2}{|c|}{$\begin{array}{l}\text { Unstandardized } \\
\text { Coefficients }\end{array}$} & \multirow{2}{*}{$\begin{array}{c}\text { Standardized } \\
\text { Coefficients }\end{array}$} \\
\hline & & $\boldsymbol{B}$ & $\begin{array}{l}\text { Std. } \\
\text { Error }\end{array}$ & \\
\hline \multirow{3}{*}{1} & (Constant) & 20,454 & 2,690 & \\
\hline & $\begin{array}{l}\text { Sikap } \\
\text { Konsumen }\end{array}$ & ,674 & 128 & ,473 \\
\hline & $\begin{array}{l}\text { Persepsi } \\
\text { Konsumen }\end{array}$ & 398 &, 125 & ,286 \\
\hline \multicolumn{5}{|c|}{ a. Dependent Variable: Keputusan Pembelian } \\
\hline
\end{tabular}

Sumber: hasil pengolahan data (2019)

Berdasarkan hasil pengolahan data pada tabel $5.10 \mathrm{di}$ atas diperoleh model persamaan $\hat{Y}=20,454+0,674 X_{1}+0,398 X_{2}$, artinya terdapat pengaruh positif antara sikap konsumen $\left(\mathrm{X}_{1}\right)$ dan persepsi konsumen $\left(\mathrm{X}_{2}\right)$ terhadap keputusan pembelian pada Mini Market Mawar Balimbingan.

\section{Analisis Korelasi dan Koefisien Determinan (KD)}

Untuk Analisis distribusi frekuensi jawaban responden menurut skor dari variabel $\mathrm{X}_{1}$ (sikap konsumen), $\mathrm{X}_{2}$ (persepsi konsumen) dan Y (keputusan pembelian) dimaksud sebagaimana telah dilakukan, hanyalah bermanfaat untuk memberikan informasi pendahuluan mengenai pola distribusi jawaban responden menurut skor. Selanjutnya dilakukan perhitungan korelasi berupa derajat atau kedalaman hubungan fungsional yang menjelaskan hubungan antara perubah yang dinamakan korelasi yang sering disimbolkan dengan Nilai r. Hasil korelasi dan koefisien determinasi dapat dilihat pada tabel yang disajikan dibawah ini:

\section{Tabel 3. Koefisien Korelasi dan Koefisien Determinasi}

\begin{tabular}{|c|c|c|c|c|}
\hline $\begin{array}{c}\text { Mode } \\
1\end{array}$ & $\overline{\mathbf{R}}$ & \begin{tabular}{|c|}
$\mathbf{R}$ \\
Square
\end{tabular} & $\begin{array}{c}\text { Adjusted R } \\
\text { Square }\end{array}$ & $\begin{array}{c}\text { Std. Error of the } \\
\text { Estimate }\end{array}$ \\
\hline 1 & .723 & .522 & .51 & 5,145 \\
\hline
\end{tabular}

Sumber: hasil pengolahan data (2019)

Dari hasil korelasi pada tabel 3 di atas diperoleh nilai $r=0,723$ yang artinya terdapat hubungan yang kuat dan positif antara sikap konsumen dan persepsi konsumen terhadap keputusan pembelian pada Mini Market Mawar Balimbingan. Kemudian diperoleh nilai koefisien determinasi $\mathrm{R}=0,522$, artinya tinggi rendahnya sikap konsumen dan persepsi konsumen terhadap keputusan pembelian sebesar $52,2 \%$ dapat dijelaskan oleh sikap konsumen $\left(\mathrm{X}_{1}\right)$ dan persepsi konsumen $\left(\mathrm{X}_{2}\right)$ sedangkan sisanya sebesar $47,8 \%$ di pengaruhi faktor lain. Menurut Hidayat (2005:6), menyatakan faktor lain yang dapat mempengaruhi keputusan pembelian adalah kualitas pelayanan, harga, dan promosi.

\section{Uji Hipotesis}

Pengujian ini dilakukan secara simultan yaitu dilakukan untuk menentukan diterima atau ditolaknya hipotesis, pengujian hipotesis dilakukan untuk mengetahui apakah variabel sikap konsumen dan persepi konsumen yang di uji berpengaruh terhadap keputusan pembelian, jika $F_{\text {hitung }}>F_{\text {tabel }}$ signifikan $\leq 0,05$ maka $\mathrm{H}_{0}$ ditolak. Dengan menggunakan bantuan program SPSS versi 21, didapatkan hasil perhitungan $F_{\text {hitung sebagai berikut: }}$

Tabel 4. Perkiraan Nilai $F_{\text {hitung }}$

\begin{tabular}{|c|c|c|c|}
\hline Model & $\begin{array}{l}\text { Sum of } \\
\text { Squares }\end{array}$ & $\mathrm{F}$ & Sig \\
\hline Regression & 4685.663 & 88.507 & $.000^{b}$ \\
\hline Residual & 4288.240 & & \\
\hline Total & 8973.903 & & \\
\hline
\end{tabular}

Sumber: hasil pengolahan data (2019)

Berdasarkan tabel 5.12 di atas diperoleh nilah $F_{\text {hitung }}$ sebesar 88,507 $>F_{\text {tabel }}$ dengan $(0,05 ; 2$ vs 162$)$ sebesar 3,05 , atau dengan signifikan $0,000<\alpha 0,05$, maka $\mathrm{H}_{0}$ ditolak, artinya sikap konsumen dan persepsi konsumen berpengaruh positif dan signifikan terhadap keputusan pembelian pada Mini Market Mawar Balimbingan.

Pengujian selanjutnya adalah uji t. 
Pengujian ini dilakukan secara parsial yaitu untuk menentukan diterima atau ditolaknya hipotesis, pengaruh hipotesis dilakukan untuk mengetahui apakah vvariabel sikap konsumen dan persepsi konsumen yang di uji berpengaruh terhadap keputusan pembelian, jika $t_{\text {hitung }}>\mathrm{t}_{\text {tabel }}$ signifikan $\alpha \leq 0,05$ maka $\mathrm{H}_{0}$ ditolak. Untuk menguji kebenarannya maka dilakukan pengujian hipotesis dengan menggunakan program SPSS versi 21.

Tabel 5. Perkiraan nilai $t_{\text {hitung }}$

\begin{tabular}{|l|c|c|}
\hline \multicolumn{3}{|c|}{ Coefficients $^{\boldsymbol{a}}$} \\
\hline Model & $\mathrm{t}$ & Sig \\
\hline Constant & 7.604 & \\
\hline Sikap Konsumen & $\mathbf{5 . 2 4 8}$ & $\mathbf{0 . 0 0 0}$ \\
\hline Persepsi Konsumen & $\mathbf{3 . 1 7 6}$ & $\mathbf{0 . 0 0 2}$ \\
\hline
\end{tabular}

Sumber: hasil pengolahan data (2019)

Berdasarkan tabel 5 di atas diperoleh nilai $t_{\text {hitung }}$ pada variabel $X_{1}$ (sikap konsumen) sebesar 5,248 $>t_{\text {tabel }}$ dengan $\mathrm{df}=\mathrm{n}-\mathrm{k}-1 \quad(165-$ $2-1=162$ ) sebesar 1,974 atau taraf signifikan $0,000<\alpha 0,05$, maka $\mathrm{H}_{0}$ ditolak, artinya sikap konsumen berpengaruh positif dan signifikan terhadap keputusan pembelian pada Mini Market Mawar Balimbingan. Hasil ini sejalan dengan penelitian yang dilakukan oleh (Tarmizi, 2017), (Abdullah, Yulianto and Mawardi, 2017), (Sulistiowati and Heryenzus, 2018), (Aryadhe, Suryani and Sudiksa, 2018)

Kemudian nilai hitung thitung pada variabel $\mathrm{X}_{2}$ (persepsi konsumen) sebesar $3,176>$ dari $t_{\text {tabel }}$ dengan df $=n-k-1,(165-2$ $1=162$ ) sebesar 1,974 atau taraf signifikan $0,002<0,05$, maka $\mathrm{H}_{0}$ ditolak artinya persepsi konsumen berpengaruh positif dan signifikan terhadap keputusan pembelian pada Mini Market Mawar Balimbingan. Hasi ini sejalan dengan penelitian (Wahyuningtyas and Widiastuti, 2017), (Wariki, Mananeke and Tawas, 2015), (Reppi, Tumbel and Jorie, 2015) (Maulana, Nawangsih and Sulistyan, 2019).

\section{Evaluasi}

\section{Sikap Konsumen Pada Mini Market Balimbingan}

Sikap disebut juga sebagai konsep yang paling khusus dan sangat dibutuhkan dalam psikologis sosial. Sikap juga merupakan salah satu konsep yang paling penting digunakan pemasar untuk memahami konsumen. Sikap konsumen pada Mini Market Mawar Balimbingan dapat dikatakan baik, hal ini dapat dilihat dari hasil kuesioner yang diperoleh dengan nilai rata-rata 3,71 dengan kriteria jawaban baik. Namun dari nilai ratarata tersebut masih ada yang memiliki nilai dibawah rata-rata seperti nilai rata-rata 3,39 dengan kriteria jawaban cukup baik pada dimensi komponen kognitif dengan indikator kesan yang muncul terkait objek. Cara mengatasinya yaitu meningkatkan kualitas pelayanan karyawan seperti membantu konsumen saat membutuhkan bantuan, sehingga akan memberikan kepuasan kepada konsumen saat melakukan pembelian.

Pada dimensi komponen perilaku dengan indikator menghargai objek memiliki nilai rata-rata 3,40 dengan kriteria jawaban cukup baik. Untuk mengatasi hal ini, Mini Market Mawar Balimbingan harus memberikan himbauan berupa petunjuk letak barang saat melakukan pembelian kepada konsumen. Dari evaluasi di atas dapat dilihat bahwa sikap konsumen pada Mini Market Mawar Balimbingan sudah dikategorikan baik. Walaupun demikian, Mini Market Mawar Balimbingan harus memperbaiki kekurangankekurangan yang ada sehingga tetap menjadi pilihan konsumen dalam melakukan pembelian

\section{Persepsi Konsumen Pada Mini Market Balimbingan}

Persepsi merupakan anggapan atau pemikiran seseorang terhadap suatu produk. Terbentuknya persepsi yang tepat pada konsumen menyebabkan seseorang memiliki kesan dan memberikan penilaian yang tepat. Persepsi konsumen terhadap keputusan pembelian pada Mini Market Mawar Balimbingan dapat dikatakan baik, hal ini dapat dilihat dari hasil kuesioner yang diperoleh nilai rata-rata 3,61 dengan kriteria jawaban baik. Namun dari nilai rata-rata tersebut masih ada beberapa indikator yang memiliki nilai rata-rata yang kurang memuaskan. Seperti pada dimensi atensi selektif dengan indikator informasi yang diterima diperoleh nilai rata-rata 3,39 dengan kriteria jawaban cukup baik. Untuk mengatasi 


\section{SULTANIST: Jurnal Manajemen dan Keuangan, Vol X (x), 2020}

hal ini Mini Market Mawar Balimbingan dapat menambahkan dan memperhatikan barcode harga barang ataupun menempel informasi terkait harga barang pada dinding sehingga memudahkan konsumen melakukan pembelian.

\section{Keputusan Pembelian Pada Mini Market Balimbingan}

Keputusan pembelian merupakan suatu tindakan yang diambil konsumen berdasarkan pertimbangan-pertimbangan untuk membeli suatu produk. Ketika konsumen melakukan pembelian, mereka akan melewati proses sebelum benar-benar mengambil keputusan untuk melakukan pembelian. Hasil pengujian terhadap variabel keputusan pembelian diperoleh nilai rata-rata 3,73 dengan kriteria jawaban baik. Namun dari nilai rata-rata ada beberapa indikator yang memiliki nilai dibawah rata-rata. Seperti pada dimensi evaluasi alternatif pada indikator sikap terhadap alternatif pilihan produk diperoleh nilai rata-rata 3,39 dengan kriteria jawaban cukup baik. Cara mengatasinya yaitu Mini Market Mawar Balimbingan perlu menyediakan stock barang lebih banyak untuk ditawarkan kepada konsumen.

Pada dimensi evaluasi pascapembelian pada indikator kepuasan dengan nilai rata-rata 3,38 dengan kriteria jawaban cukup baik. Untuk mengatasinya Mini Market Mawar Balimbingan perlu menambah volume penjualan produk serta variasi produk sehingga konsumen akan melakukan pembelian ulang.

Dari evaluasi di atas dapat disimpulkan bahwa keputusan pembelian pada Mini Market Mawar Balimbingan sudah dikategorikan baik. Namun masih ada beberapa indikator yang rendah sehingga perusahaan perlu memperbaiki kekurangan-kekurangan yang ada untuk meningkatkan penjualan.

\section{KESIMPULAN DAN SARAN}

\section{Kesimpulan}

Hasil analisis regresi linear berganda yang dihitung melalui aplikasi SPSS versi 21 dapat disimpulkan bahwa terdapat pengaruh yang positif antara sikap konsumen dan persepsi konsumen terhadap keputusan pembelian. Selanjutnya hasil analisis korelasi yang diperoleh membuktikan terdapatnya hubungan yang kuat dan positif antara sikap konsumen, persepsi konsumen, dengan keputusan pembelian. Tinggi rendahnya keputusan pembelian dapat dijelaskan oleh sikap konsumen dan persepsi konsumen. Kemudian hasil pengujian hipotesis secara simultan dengan uji $\mathrm{F} \mathrm{H}_{0}$ ditolak, artinya terdapat pengaruh yang positif dan signifikan antara variabel sikap konsumen dan persepsi konsumen terhadap keputusan pembelian. Hasil pengujian hipotesis secara parsial dengan uji $\mathrm{t} \mathrm{H}_{0}$ ditolak, artinya terdapat pengaruh positif dan signifikan antara sikap konsumen dan persepsi konsumen terhadap keputusan pembelian.

\section{Saran}

Berdasarkan kesimpulan di atas, maka perlu dikemukakan beberapa saran yang dapat berguna bagi perusahaan yaitu, untuk meningkatkan sikap konsumen, Mini Market Mawar Balimbingan perlu meningkatkan kualitas pelayanan yang akan memberikan kepuasan kepada konsumen saat melakukan pembelian. Lebih lanjut, untuk memberikan persepsi yang baik kepada konsumen, Mini Market Mawar Balimbingan perlu meningkatkan penjualan dengan cara menjual produk kebutuhan yang tidak dijual di Mini Market lainnya. Selanjutnya untuk meningkatkan keputusan pembelian di Mini Market Mawar Balimbingan perlu menambah volume penjualan produk serta variasi produk sehingga konsumen akan melakukan pembelian ulang.

\section{DAFTAR PUSTAKA}

Abdullah, R., Yulianto, E. and Mawardi, M. (2017) 'Pengaruh Sikap, Faktor Pribadi, Dan Faktor Sosial Terhadap Keputusan Pembelian (Survey pada Konsumen Kartu Perdana SimPATI di GraPARI Malang)', Jurnal Administrasi Bisnis S1 Universitas Brawijaya, 42(1), pp. 110114.

Aryadhe, T., Suryani, A. and Sudiksa, I. B. 


\section{SULTANIST: Jurnal Manajemen dan Keuangan, Vol X (x), 2020}

(2018) 'Pengaruh Sikap dan Norma Subjektif Terhadap Niat Beli dan Keputusan Pembelian', E-Jurnal Manajemen Unud, 7(3), pp. 1452-1480. Maulana, M. F., Nawangsih and Sulistyan, R.

B. (2019) 'Pengaruh persepsi Konsumen dan Motivasi Konsumen Terhadap Keputusan Pembelian Karti Perdama IM3', Jurnal Riset Manajemen, 2(1), pp. 78-88.

Boyd, et.al. 2000. Manajemen Pemasaran. Jakarta : Erlangga.

Kotler, Philip \& Gary Armstrong. 2008. Prinsip-Prinsip Pemasaran. Edisi XII. Jakarta : Erlangga.

Kotler, Philip \& Kevin Lane Keller. 2009. Manajemen Pemasaran. Jilid I. Jakarta : Erlangga.

Reppi, J. M., Tumbel, A. and Jorie, R. J. (2015) 'Analisis Pengaruh Persepsi Kualitas, Motivasi Dan Sikap Konsumen Terhadap Keputusan Pembelian Ponsel Iphone Pada Pusat Perbelanjaan Itc Manado', Jurnal Berkala Ilmiah Efisiensi, 15(828-838), p. $1 . \quad$ Available at: https://ejournal.unsrat.ac.id/index.php/jb ie/article/viewFile/10499/10087.

Schiffman, Leon \& Leslie Lazar Kanuk. 2007. Perilaku Konsumen. Edisi VII. Jakarta : Indeks.

Setiadi, Nugroho J. 2003. Perilaku Konsumen. Jakarta : Kencana.

Sulistiowati, I. and Heryenzus (2018) 'Pengaruh Sikap Dan Kepercayaan Terhadap Keputusan Pembelian Produk Online (Studi Kasus Pada Online Shop Grostas Import Batam)', Jurnal Ilmiah Manajemen UPB, 6(1), pp. 19-26.

Sumarwan, Ujang. 2002. Perilaku Konsumen. Bogor: Ghalia Indonesia.

Tarmizi, A. (2017) 'Analisis Sikap Konsumen Terhadap Keputusan Pembelian Produk Sepeda Motor Honda Merek Vario Pada Pd. Daya Motor Sungai Bahar Muaro Jambi', EKONOMIS: Journal of Economics and Business, 1(1), p. 18. doi: 10.33087/ekonomis.v1il.4.

Wahyuningtyas, Y. F. and Widiastuti, D. A. (2017) 'Analisis Pengaruh Persepsi Risiko, Kemudahan Dan Manfaat
Terhadap Keputusan Pembelian Secara Online (Studi Kasus Pada Konsumen Barang Fashion Di Facebook)', Kajian Bisnis STIE Widya Wiwaha, 23(2), pp. 112-120. doi: 10.32477/jkb.v23i2.208.

Wariki, G. M., Mananeke, L. and Tawas, H. (2015) 'Pengaruh Bauran Promosi, Persepso Harga dan Lokasi Terhadap Keputusan Pembelian dan Kepuasan Konsumen Pada Perumahan Tamansari Metropolitan Manado', Jurnal Pendidikan Tata Niaga (JPTN), 3(2), pp. 1073-1085.

Winardi, J. 2009. Manajemen Perilaku Organisasi. Jakarta : Kencana.

\section{Profil Singkat}

Siti Fadhila, Lahir di Dolok Marubun, tanggal 31 Agustus 1996, lulus dari jurusan Sarjana Manajemen Sekolah Tinggi Ilmu Ekonomi Sultan Agung pada tahun 2019. Darwin Lie, Gelar doktor diperoleh dari Universitas Pasundan Bandung dengan konsentrasi ilmu manajemen dan lulus pada tahun 2018. Andy Wijaya, gelar magister manajemen diperoleh dari Program Magister Manajemen Fakultas Pascasarjana Universitas HKBP Nommensen Medan dan lulus pada tahun. Gelar doktor diperoleh dari Universitas Pasundan Bandung dengan konsentrasi ilmu manajemen dan lulus pada tahun 2018. Fitria Halim, gelar magister manajemen diperoleh dari Program Magister Manajemen Fakultas Pascasarjana Universitas HKBP Nommensen Medan dan lulus pada tahun 2014. 